\title{
A task of terawatts
}

\author{
The world has an abundance of renewable energy to offer, the question is how to harness it.
}

T he ultimate answer to humanity's energy problems rises every morning and sets every evening. The Sun shines down on Earth with a power of 174,000 terawatts. It lifts water from the surface of the sea to fall back down on the high mountains of the land; drives ocean currents from the tropics to the poles; spins winds around the world; and powers the green engine of life, producing practically every calorie ever consumed on Earth.

Unfortunately, humanity is now, like Hamlet, too much in the Sun. Solar energy, reduced to waste heat, no longer leaves the planet as easily as it once did. Instead it tarries in the atmosphere, thanks to the ever stronger greenhouse effect. This change in the planet's energy balance is a small one - but so great is the flow of energy from the Sun that, over decades and centuries, it will do terrible damage.

Clearly, society must slow and eventually halt the rate at which the greenhouse effect is being strengthened. The best way to achieve this, as this journal has argued on many occasions, is to increase the cost of emitting carbon dioxide and other greenhouse gases, through a capand-trade scheme, or possibly a direct carbon tax. But for this strategy to work there must be attractive alternative sources of energy.

The tendency among governments and traditional utilities to see renewable energy sources as oddities or add-ons is thus deeply misplaced. These sources are the future; the only question is how fast we can harness their potential. On page 816 of this issue, we survey the carbon-free technologies currently on offer. For the most part they are driven by the Sun - either directly, or via the indirect means of wind, water and plants - and it is striking to see how much they have to offer. Many of these technologies offer more than a terawatt of additional global capacity, and all have ample room for growth. Today's largest, hydropower and nuclear power, could grow by a factor of two or more - albeit with potentially troublesome nonclimate consequences. But the greatest proportional capacity for growth lies with the current small-fry contributors. Wind turbines, for example, offer much greater possibilities for improvement than hydroelectric plants; the technologies for harnessing the wind far out to sea - or, for that matter, in the high currents of the jet-stream - are still comparatively immature. And even wind does not have the ultimate potential promised by the direct use of sunlight. In the future, new manufacturing methods that use alternative materials should make the capture of sunlight at least an order of magnitude cheaper than it is now.

\section{Ideas and incentives}

The challenge is how to scale these new technologies up for a global market. A significant part of the answer is investment in focused research and development. Sadly, in most of the world, government spending on research in the energy sector has been stagnant or worse for decades. That has to change. Also crucial is an entrepreneurial culture that can get new ideas to mass markets. That requires both a social network geared to innovation and a supply of ready capital. The news here is good: in areas such as Californiass Silicon Valley there is intense interest in solar energy, for example, and the industry is well positioned to exploit the same entrepreneurial vigour that has made computers and communications successful over the past few decades.

Still, enthusiastic venture capitalists will not be enough. Firms with new energy technologies need to be able to access the capital of the stock markets if they are to grow large enough to change the world. One way to make such firms attractive to investors is to guarantee them sales. This can be done through regulation - insisting on a certain "The challenge is not how to save the world most efficiently - just how to save the world." amount of renewable energy in all new developments, say - through subsidy, or through direct intervention; there is nothing to stop governments from acting as bulk buyers of new capacity. Governments would be wise, though, not to indulge protectionist tendencies in the process. For investors in Texas to know that they can sell in Beijing, and for a Bangalorean to be sure of a market in Brazil, is a great benefit.

\section{Careful investment}

Finding economically efficient ways to stimulate the growth of a particular industry is not easy. The types of subsidy that have worked to date - such as the feed-in inducements that have built Germany its solar-cell industry - are expensive even at the megawatt scale. At the scale of tens and then hundreds of gigawatts they are likely to be unsustainable. Perhaps worse than the cost, though, is the risk that poorly designed subsidies will damage markets and thwart the development they seek to encourage. However, this is a challenge to encourage technologies in a smart and flexible way, not a reason to leave the markets alone. The challenge is not how to save the world most efficiently - just how to save the world. Getting to the right place the wrong way is better than going nowhere, even if waste is involved.

There is much else to do. For example, one solution to the problem of energy storage may be found in the development of plug-in hybrid cars, which can take electricity out of a smart grid but also put it back (see page 810).

Imaginative, energetic, organized action may require new institutions. The next US president could send a strong signal of his country's seriousness by creating a well-funded Department of Renewable Energy. The development and uptake of new technologies around the world might also be encouraged by an International Renewable Energy Agency, charged with research, transmitting best practice, removing bottlenecks, and so on. But new institutions are not enough. There are interest groups that will naturally oppose this transition, and they will need to be dealt with by robust and resolute political leadership.

Even to a technoenthusiast, the scale of what needs to be done is daunting. But the wind keeps blowing, the grass keeps growing, and the Sun keeps shining. The energy is there. 